\title{
Synaptonemal complex studies of the common shrew (Sorex araneus). Comparison of Robertsonian heterozygotes and homozygotes by light microscopy
}

\author{
B. M. N. Wallace* and \\ J. B. Searletђ
}
* Department of Biological Sciences, University of Birmingham, PO Box 363, Birmingham B15 2TT, U.K. $\uparrow$ Department of Zoology, University of Oxford, South Parks Road, Oxford OX1 3PS, U.K.

Chromosome pairing at prophase I of meiosis was orderly in the common shrew. The frequency of univalance was low and nonhomologous pairing between bivalents or involving the sex trivalent (XY1Y2) was absent. The true $X$ and $Y$ chromosomes were attached in an end-to-end configuration. In "simple" Robertsonian heterozygotes autosomal trivalents were formed. Most of these ( 64 per cent) exhibited straight pairing. Otherwise, side arms were formed from the centromeric regions of the acrocentrics which were almost invariably in a cis orientation and usually paired with each other.

\section{INTRODUCTION}

The pattern of karyotypic variation and evolution in the common shrew (Sorex araneus) has attracted much interest (reviewed in Searle, 1988a). The major class of structural mutation in the recent history of this species has been the Robertsonian (centric) usion, in which a pair of acrocentric chromosomes join at their centromeres to form a single metacentric chromosome. The complement of such metacentric chromosomes differs between the large number of karyotypic races of the common shrew and polymorphism (within-population variation) has been demonstrated in many localities, particularly in the vicinity of interracial hybrid zones. Here, Robertsonian heterozygotes are found, often at high frequency (e.g., Searle, $1986 a$ ). These have karyotypes in which particular chromosome arms are found in both an acrocentric and a metacentric state ("simple" Robertsonian heterozygotes) or as part of two different metacentrics ("complex" Robertsonian heterozygotes).

Karyotypic heterozygosity is well-known to be associated with disruption of meiosis. Meiotic

Dedicated to the late Professor Sir Kenneth Mather FRS in gratitude for his advice and encouragement.

$\ddagger$ To whom correspondence should be addressed. aberrations associated with Robertsonian heterozygosity can lead to impaired fertility in mammals, as has been demonstrated most clearly in the house mouse (Gropp and Winking, 1981; Redi and Capanna, 1988; Searle, 1988b). In particular, there may be either a failu re of homologues to disjoin correctly at anaphase I resulting in unbalanced gametes (Ford, 1972), or a more generalised atresia of meiocytes (recent reviews: Burgoyne and Baker, 1984; Richler et al., 1989).

Chromosome synapsis and chiasma formation are prerequisites for the correct disjunction of homologous chromosomes; thus, any failure to pair may result in aneuploid gametes. Furthermore, in mammals, pairing irregularities may lead to germ cell death through inappropriate expression of genes at regions of autosomal asynapsis (Burgoyne and Baker, 1984) or on the sex chromosomes (in the male) if there is interaction with asynaptic autosomal regions (Richler et al., 1989). The role of chromosome pairing is therefore central to orderly meiosis. Previous studies have indicated that, in Robertsonian heterozygotes, the pairing of the heteromorphic chromosomes is particularly prone to abnormality (e.g., Rosenmann et al., 1985; de Boer, 1986). 
To date, meiotic studies in the common shrew have concentrated on the stages of diakinesis, metaphase I and metaphase II (Sharman, 1956; Meylan, 1964; Fredga, 1970; Halkka et al., 1974; Fedyk, 1980; Searle, 1986b) but in view of the link between chromosome pairing, nondisjunction and germ cell death, it was considered important to examine earlier meiotic stages when pairing occurs.

During prophase I of meiosis, homologous chromosomes are held in register by a synaptonemal complex (SC) which forms at zygotene, persists throughout pachytene and accurately represents the synaptic behaviour of the chromosomes (Moses, 1977; Moses et al., 1979; Jones and Wallace, 1980). The SC complement can be displayed by surface-spreading to allow analysis by light or electron microscopy (Hultén et al., 1985). In this study we used a silver staining protocol to visualise the SCs by light microscopy. While this did not allow observations as detailed as can be obtained by electron microscopy, it permitted us to score large numbers of cells (252) in several individuals (10), thereby providing an overview of the behaviour of chromosomes at pachytene in wildcaught common shrews, homozygous or heterozygous for a variety of Robertsonian rearrangements. The animals were collected from the vicinity of the city of Oxford (U.K.) in an area of Robertsonian polymorphism associated with the zone of hybridisation between the Oxford karyotypic race to the north and the Hermitage karyotypic race to the south (Searle, 1986a; 1988a).
In this paper we follow the nomenclature used by Searle (1986a) for the description of common shrew karyotypes. The arms of the autosomes are designated $a-u, a$ being the largest and $u$ the smallest. In the individuals studied, metacentric chromosomes $a f, b c, h i, g m, j l$ and $t u$ were invariant. Chromosome arms $k, n, o, p, q$ and $r$ displayed polymorphism and occurred combined as metacentrics $k q$, no or $p r$ (which characterise the Oxford race) or ko (Hermitage race) in a homozygous $(\mathrm{M})$ or heterozygous $(\mathrm{H})$ state or alternatively as acrocentrics (A). Homozygotes, ranging from individuals with a fully metacentric karyotype to individuals maximally acrocentric, and "simple" heterozygotes for 1, 2 or 3 arm combinations, were analysed (table 1). In simple Robertsonian heterozygotes, a metacentric is expected to pair with two homologous acrocentrics at zygotene/pachytene to form a heteromorphic trivalent configuration. Certainly, regular trivalents are observed at diakinesis/metaphase I in such individuals (Searle, 1986b).

The sex chromosome complement of common shrews is unusual. The true $X$ chromosome has been joined by Robertsonian fusion onto an autosome (Searle, 1983). Therefore, male shrews have an XY1Y2 sex chromosome constitution where $\mathrm{Y} 1$ is the true $\mathrm{Y}$ and $\mathrm{Y} 2$ the unattached autosome (Sharman, 1956; Fredga, 1970). During zygotene/pachytene these are expected to form a sex trivalent; such a configuration is recorded at diakinesis/metaphase I (Searle, 1986b).

Table 1 Karyotypes, numbers of synaptonemal complexes (SCs) and autosome-sex chromosome contacts in spermatocytes of common shrews

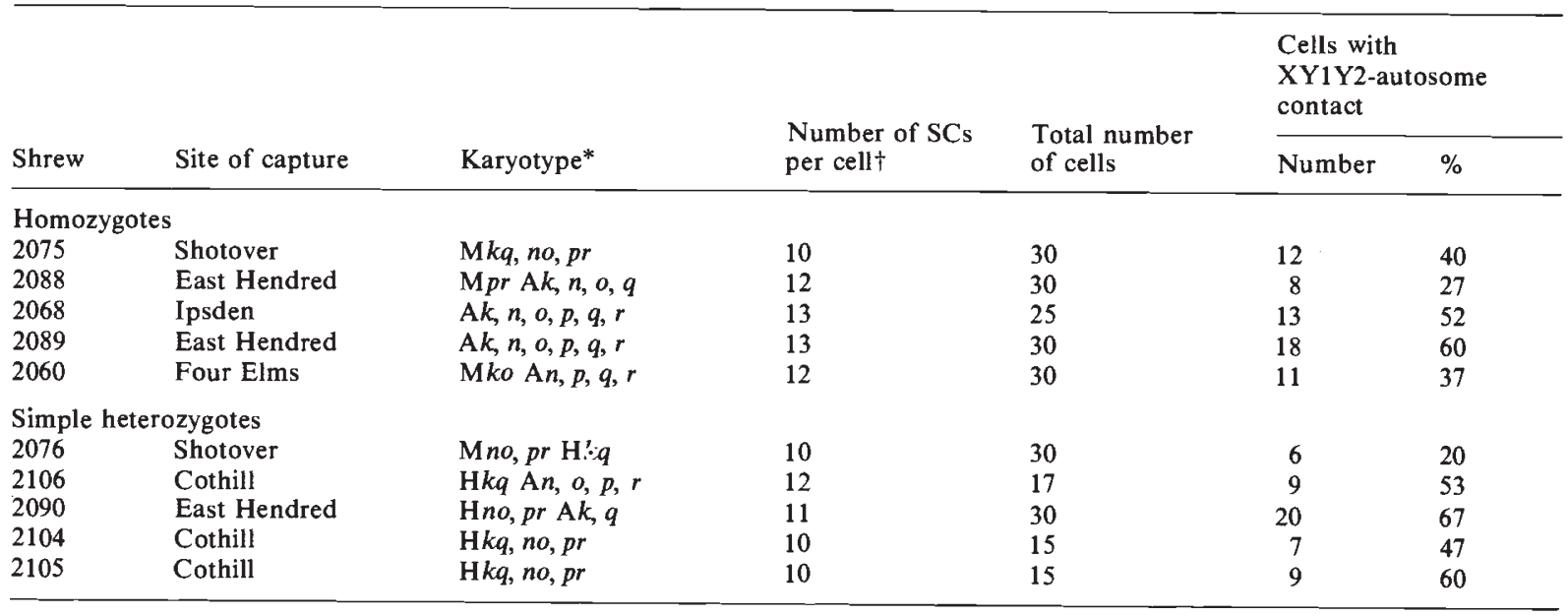

* M, homozygous metacentric; $\mathrm{H}$, heterozygous; $\mathrm{A}$, homozygous acrocentric.

$\dagger$ Includes the sex trivalent. 


\section{MATERIAL AND METHODS}

Ten adult male common shrews were collected from five sites in the vicinity of Oxford, U.K.: Shotover (grid reference 455/205), Cothill (446/199), Ipsden (462/184), East Hendred $(445 / 185)$ and Four Elms (451/174). The shrews at Shotover and Cothill have an Oxford race karyotype, those at Four Elms are of the Hermitage race type while Ipsden and East Hendred are in the hybrid zone between the Oxford and Hermitage races. The animals were collected between late March and mid May 1988, at the peak of the breeding season. In every animal, histology of the left testis was normal and the weight of the combined testes exceeded $50 \mathrm{mg}$. On these criteria alone, all may be considered to have been fertile (Brambell, 1935).

After capture, the animals were maintained in individual cages with natural illumination for up to 11 days and killed by cervical dislocation. The karyotype was determined from G-banded bone marrow preparations (Searle, 1986a). The right testis of each animal was used for surfacespreading by a modified method of Hultén et al. (1985), as follows: One drop of a spermatocyte suspension was added to two drops of a spreading medium (either the detergents 0.03 per cent "Joy" or 0.02 per cent "Lipsol" both buffered with $0.01 \mathrm{M}$ sodium tetraborate $p \mathrm{H} 8.5$, or an unbuffered solution of $0.2 \mathrm{M}$ sucrose) on a greasefree microscope slide. After six minutes the cells were fixed by adding five drops of 4 per cent paraformaldehyde buffered with $0.2 \mathrm{M}$ sodium tetraborate $p \mathrm{H} 8 \cdot 5$ (Moses, 1977) and dried on a hot plate, at $34^{\circ} \mathrm{C}$, for at least $1 \mathrm{hr}$. Following fixation, slides were washed in distilled water, air dried and stained with 50 per cent silver nitrate in 0.04 per cent formalin by the method of Kodama et al. (1980).

\section{RESULTS}

For each of the ten shrews studied, the number of SCs observed in pachytene cells was as expected from the G-band karyotype (table 1). Pairing was complete in most cells (figs 1 and 2) and where there was incomplete pairing it was confined to one or a few configurations within a cell. Differences in the overall characteristics of the 252 pachytene cells scored were, in general, of a minor nature and it was not possible to allocate cells into specific substages of pachytene.
The XY1Y2 sex trivalent was usually identifiable by size and a "wavy" or "hooked" appearance. It exhibited straight pairing with no obvious XY1 pairing segment (figs 1 and 2); our interpretation of the pattern of pairing is given in fig. 3(c). Despite the presumptive lateral pairing of the $\mathrm{Y} 2$ chromosome and autosomal part of the $\mathrm{X}$, in contrast to unpaired regions of the true- $X$ segment and the Y1 chromosome, no differentiation along the sex trivalent was observed. Excrescences, indicative of unpaired regions (Johannisson et al., 1983) were associated with the sex trivalent in 44 per cent of cells examined (fig. 1).

Nucleolar organiser regions (NORs) could be localised from the nearby presence of darkly staining nucleolar material (figs 1 and 2). NORs were present near the distal ends of chromosome arms $o, q, t$ and $u$ (identified by (SC) lengths and centromere positions) in general agreement with the positions noted by Ag-NOR staining of mitoses (Olert and Schmid, 1978; Halkka and Söderlund, 1987 ) and the positions of mitotic secondary constrictions (Searle, 1983). The amount of nucleolar material varied between individuals from very little in shrew 2068 to an abundance dispersed over the whole nucleus as well as at the NORs of the bivalents in shrew 2106 .

Univalents were present in 11 cells $(4 \cdot 4$ per cent of the total). Three of these cells apparently had an univalent $Y 1$, six cells had an additional autosomal element, one cell had two additional autosomal elements and one cell had both a univalent $\mathrm{Y} 1$ and an additional autosomal element. In two instances, single univalents could have resulted from a pairing aberration of an autosomal trivalent. Univalence involved the smaller autosomes but was not confined to a specific configuration. There was no indication that univalence was more prevalent in heterozygotes than in homozygotes or that the degree of heterozygosity affected the degree of univalence. The highest incidence of univalence was in a homozygous individual (2089: table 1) in which 13 per cent of cells contained univalents.

Between 15 and 30 well-spread cells were scored per individual for the presence of a contact between the sex trivalent and autosomal configurations (table 1). In other species an interaction between the autosomal trivalent and the sex chromosomes is observed in Robertsonian heterozygotes, and may be related to germ cell death (e.g., Rosenmann et al., 1985). Overall, in 43 per cent of cells from homozygotes and 48 per cent of cells from heterozygotes there was contact between the sex trivalent and an autosomal 


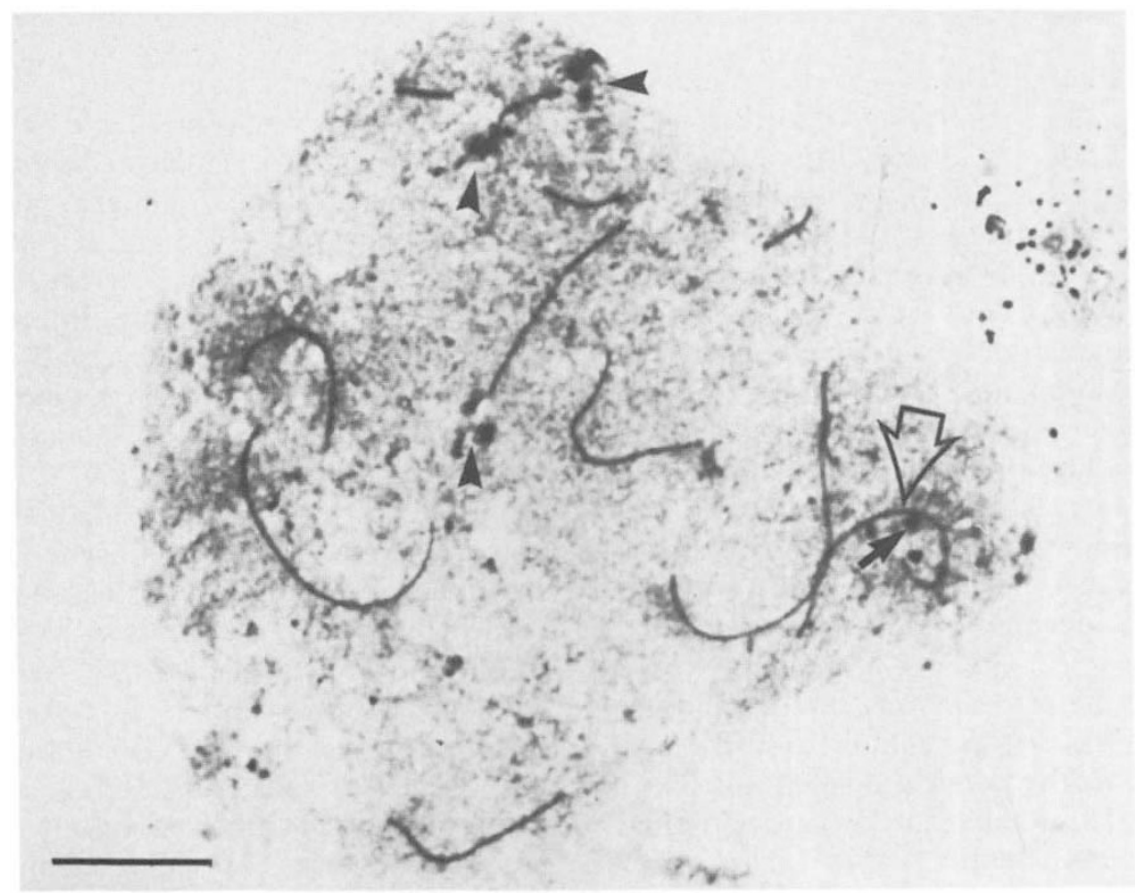

Figure 1 Synaptonemal complexes in a spermatocyte of shrew 2060, homozygous metacentric for ko and homozygous acrocentric for $n, p, q$ and $r$. Note overlap of sex trivalent (open arrow) with a large autosomal bivalent and excrescences (small arrow) associated with the true X segment. Nucleolar material (arrow heads) associated with chromosome arms $o, t$ and $u$ (but not $q$ in this cell). Centromeres not evident. Scale bar: $10 \mu \mathrm{m}$.

configuration (table 1). However, there was substantial heterogeneity between individuals, varying from 20 to 67 per cent of cells with one or more "contacts" in different heterozygous individuals. Contact between autosomal trivalents and sex trivalents was found in a minimum of three cells and a maximum of eight cells in Robertsonian heterozygotes $(2 \cdot 8-7 \cdot 5$ per cent of the total number of cells from heterozygotes). However, contacts between the sex trivalent and the longest of the autosomal bivalents were considerably more frequent in both homozygotes and heterozygotes. Overall, 73 per cent of the autosomal configur- ations in contact with the sex trivalent could be categorised as one of the four longest bivalents. This is as expected if the overlaps represent chance juxtaposition of SCs during spreading. Therefore, there was no indication of either a preferential association between the autosomal trivalents and the sex trivalent in Robertsonian heterozygotes, or nonhomologous pairing involving the sex trivalent.

Among the Robertsonian heterozygotes screened, there were shrews in which one, two or three autosomal trivalents were expected (table 2). The majority of trivalents exhibited straight pairing (64 per cent), such that no side arm was visible

Table 2 Characteristics of autosomal trivalent configurations

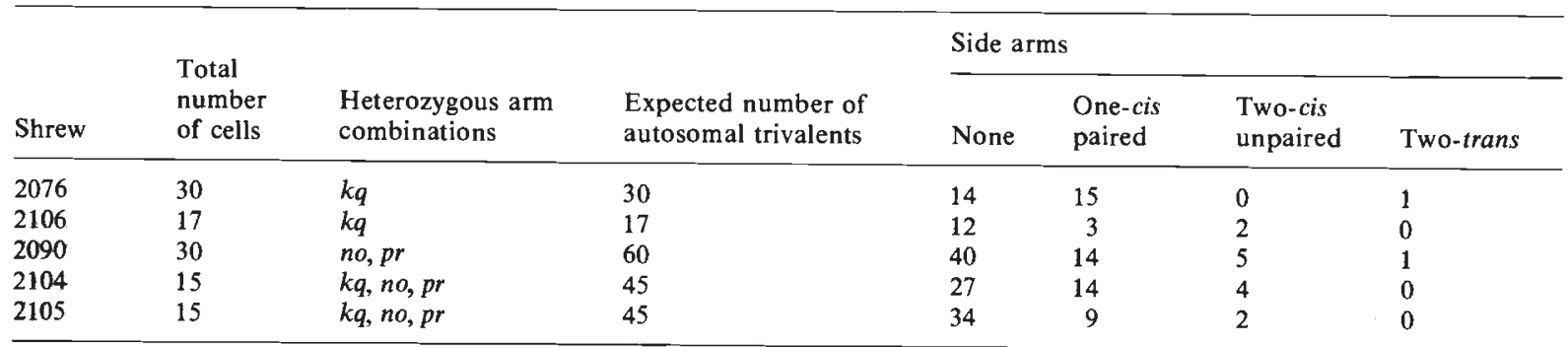




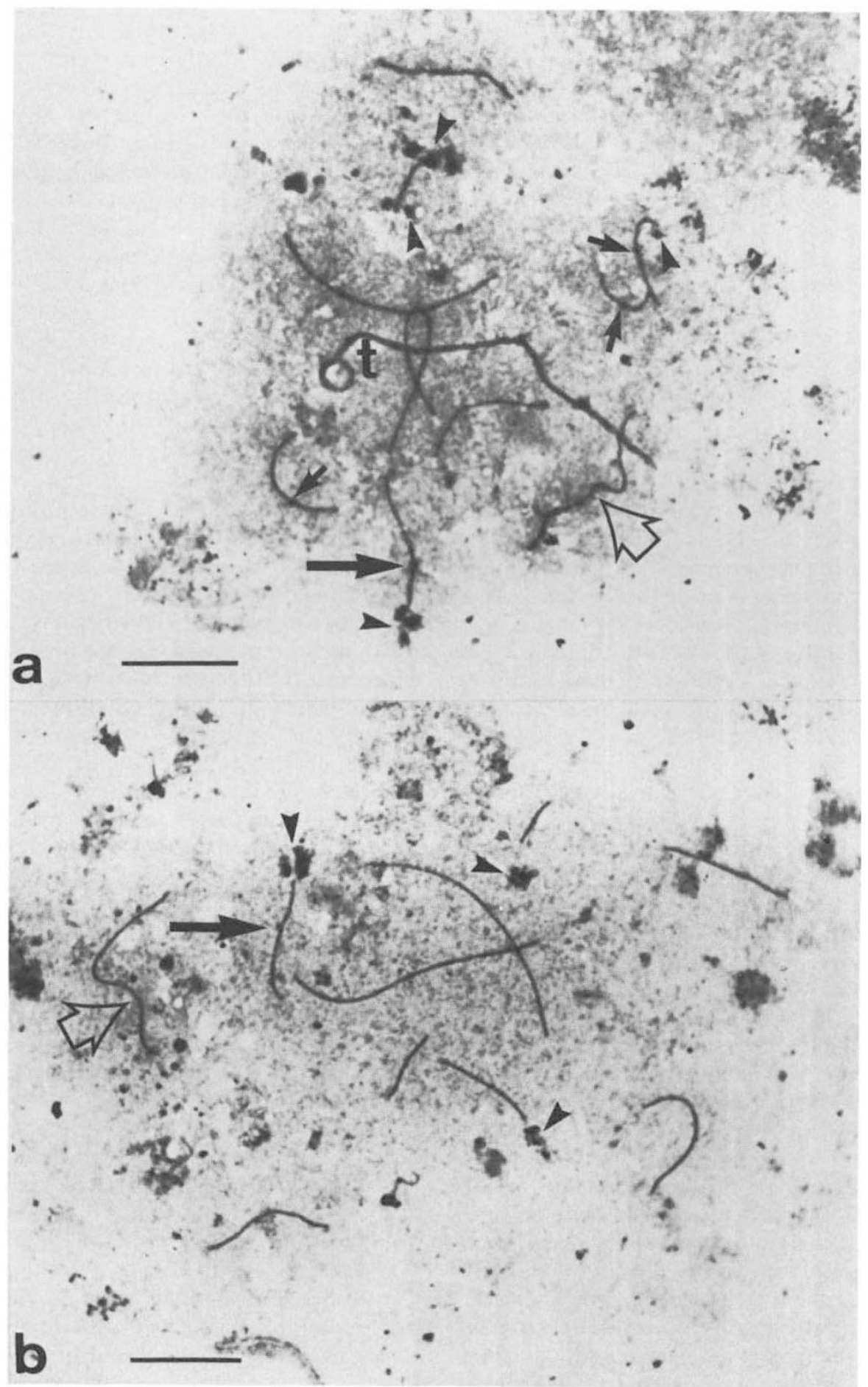

Figure 2 Synaptonemal complexes in spermatocytes of shrew 2076, heterozygous for $\mathrm{kq}$ and homozygous metacentric for no and pr. Autosomal trivalent (large closed arrows) exhibits straight pairing in spermatocyte a, while a "short side arm" is visible in spermatocyte $b$. Centromeres (small arrows) clearly visible in cell a which has nucleolar material (arrow heads) associated with chromosome arms $o, q, t$ and $u$ (absent from either $t$ or $u$ in cell b). A sperm tail (t) and the sex trivalent (open arrows) are also indicated. Scale bar: $10 \mu \mathrm{m}$. 
(figs 2(a) and 3(a)). In the next most common condition ( 28 per cent of trivalents) there was a single, exceedingly small side arm (figs 2 (b) and $3(\mathrm{~b}))$. This probably represented the centromeric regions of the two acrocentric chromosomes in cis configuration and paired with each other. In some cases these centrometric regions were unpaired, but still in the cis configuration ( 7 per cent of trivalents). Only very rarely were two unpaired short arms observed in the trans configuration (1 per cent of trivalents). It has been suggested that the cis configuration favours correct disjunction (Moses et al., 1979). However, the distinction between cis and trans configurations of unpaired regions could be an artifact of spreading.

\section{DISCUSSION}

Our analysis of SCs shows that chromosome synapsis is normally complete in shrew spermatocytes and that there is no tendency for partial pairing of autosomes or nonhomologous pairing between configurations. However, there was a degree of univalence, with the incidence at pachytene (4.36 per cent of cells over all ten individuals) remarkably similar to that found at diakinesis/metaphase I (4.39 per cent: Searle, $1986 b)$. This suggests that rather more univalence is the result of asynapsis or desynapsis during pachytene than suggested previously (Searle, $1986 \mathrm{~b})$. A greater proportion of this univalence could be attributed to univalence of the $\mathrm{Y} 1$ at diakinesis/metaphase I (55-68 per cent) than at pachytene (31 per cent). No individual was found with an exceptionally high incidence of univalence and the highest (13 per cent of cells) in an individual at pachytene was similar to that ( 18 per cent) found previously at diakinesis/metaphase I (Searle, 1986b). There is no evidence of an association between the karyotype of an individual and the degree of univalence at pachytene.

The features of pairing of the autosomal trivalent in simple Robertsonian heterozygotes were very regular in the common shrew. For the majority of trivalents, there was complete synapsis between the acrocentrics and metacentric. This suggests that each acrocentric corresponds almost exactly to one arm of the metacentric, as is also indicated by G-band studies of mitotic chromosomes (Halkka et al., 1974; Olert and Schmid, 1978). However, due to the possible occurrence of nonhomologous pairing, the close pairing does not necessarily mean absolute homology of the metacentric with the acrocentrics. In some trivalents the centromeric regions of the acrocentric do apparently pair nonhomologously to form a minute side-arm. Occasionally, the centromeric regions of acrocentrics and metacentrics were observed to be unpaired on the trivalent. By analogy with other species (e.g., cattle: Świtoński et al., 1987), this probably reflects late pairing rather than a complete absence of pairing.

Unpaired regions of autosomes may lead to germ cell death, perhaps by interaction with the sex chromosomes in the male (Burgoyne and Baker, 1984; Richler et al., 1989). Certainly, there was no indication of association of autosomal trivalent and sex chromosomes in common shrew spermatocytes in contrast with Robertsonian trivalents in mouse (de Boer, 1986) and man (Rosenmann et al., 1985), in which male simple Robertsonian heterozygotes may suffer substantial germ cell death. Nor do common shrews that are simple Robertsonian heterozygotes suffer such germ cell losses (Garagna et al., 1989).

The complete synapsis of metacentric and two acrocentrics as is usual in pachytene trivalents of Robertsonian heterozygous common shrews, is not general to other species. Some trivalents in cattle exhibit straight pairing (Świtoński et al., 1987), but pachytene trivalents in Robertsonian heterozygotes of man, mouse, lemur, cotton rats and the rodent Ellobius have distinct side arms formed by synapsis of the centromeric regions of the acrocentrics (Rosenmann et al., 1985; Gropp and Winking, 1981; Moses et al., 1979; Elder and Pathak, 1980; Bogdanov et al., 1986). In some instances, this may reflect nonhomologous pairing in response to obvious structural differences in the centromeric region between the metacentric and acrocentrics, e.g., in man (Gosden et al., 1981). However, in the mouse, there is no detectable difference in DNA content between the metacentric and homologous acrocentrics in Robertsonian heterozygotes (Coming and Avelino, 1972; Redi et al., 1986). Also, in the cotton rat there are very clear side arms (that persist until diplotene) on Robertsonian trivalents, but no G-band or C-band differences between the metacentric and homologous acrocentrics (Elder and Pathak, 1980). Why there should be side arms in Robertsonian trivalents of the mouse and cotton rat is unknown. In the mouse there may be earlier pairing between the centromeric ends of the acrocentrics than between other parts of the centromeric region $(H$. Winking, personal communication) and this event (perhaps reflecting underlying sequence homology) could initiate substantial nonhomologous pairing. Alternatively, the nonhomologous pairing may reflect real, albeit 


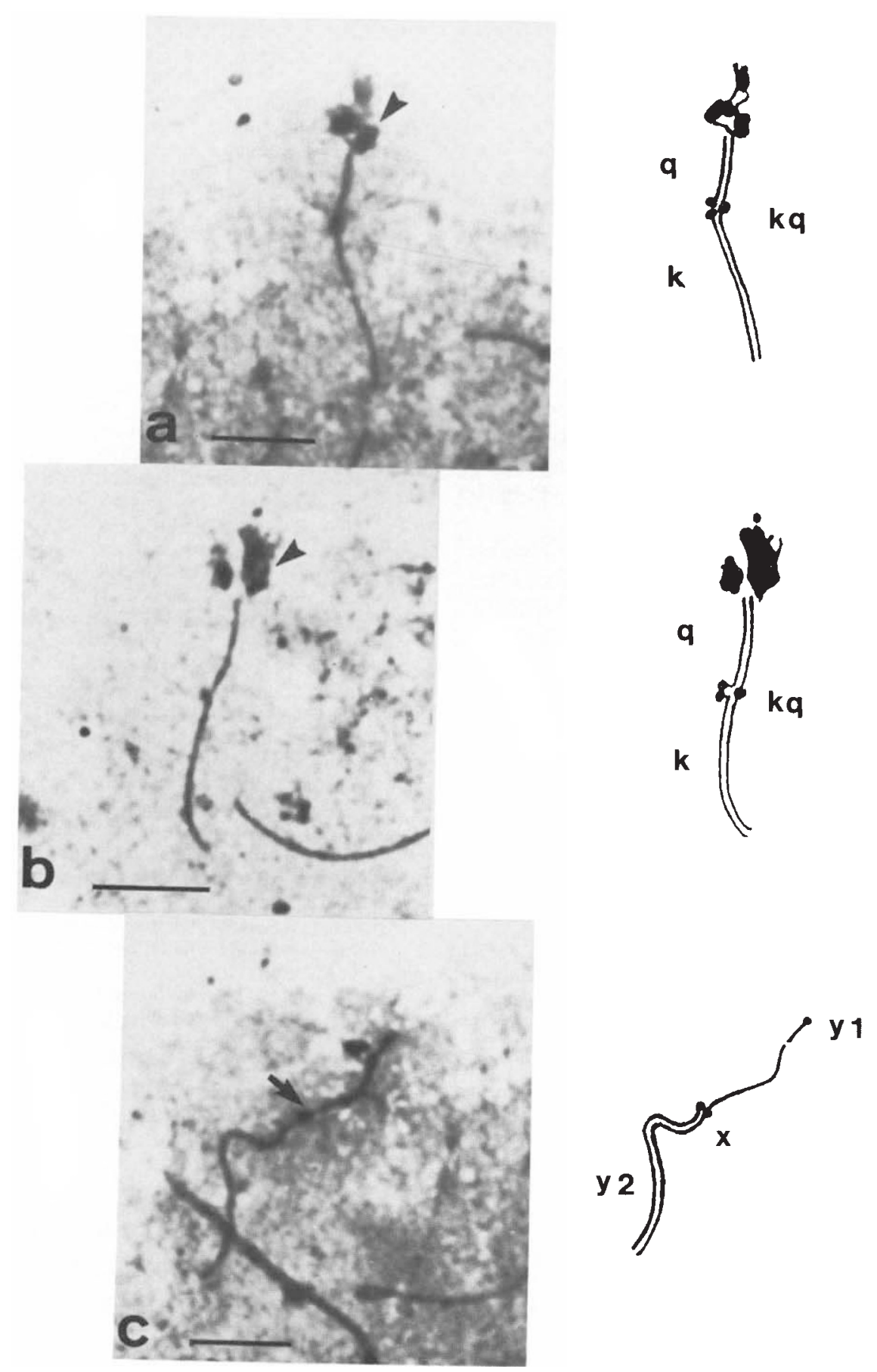

Figure 3 Enlargement of the autosomal trivalents $k q(\mathrm{a}, \mathrm{b})$ and the sex trivalent (c) with interpretive diagrams. The trivalents in $\mathrm{a}$ and $\mathrm{c}$ both exhibit straight pairing at pachytene. Presumptive positions of centromeres (O) are indicated on the diagrams. Nucleolar material (arrow heads), excresences on unpaired X (small arrow). Scale bar: $5 \mu \mathrm{m}$. 
small, structural differences between the acrocentrics and metacentrics (recent evidence in the mouse does suggest that metacentrics have only one centromere: Wolf and Winking, 1989).

As with the autosomal trivalents, the sex trivalent in shrew spermatocytes apparently pairs in a generally orderly fashion. The synapsis between the $\mathrm{X}$ chromosome (i.e., the $\mathrm{X}$-autosome fusion) and $\mathrm{Y} 2$ (i.e., the unattached autosome) is complete and the Y1 (i.e., the true Y) shows an "end-to-end" attachment with the true-X segment of the $X$ chromosome. Similar results were obtained for the XY1Y2 sex trivalent in the rabbiteared bandicoot (Sharp, 1982). The muntjac forms an XY1Y2 trivalent but displays a distinct pairing region between the $X$ and $Y 1$ at pachytene, which projects as a short arm from the trivalent (Pathak and Lin, 1982).

Electron microscopical investigations, which are in progress, should provide more details of the pairing process in the common shrew, for both the sex trivalent and autosomal trivalents in Robertsonian heterozygotes.

Acknowledgements We would like to thank Simon Mercer for help with collection and maintenance of animals and technical assistance, Dr Heinz Winking for discussions and Dr Angela Douglas for reading the manuscript. J.B.S. is supported financially by the Royal Society of London.

\section{REFERENCES}

BOER, P. DE 1986. Chromosomal causes for fertility reduction in mammals. In de Serres, F. J. (ed.) Chemical Mutagens, vol. 10, Plenum, New York, pp. 427-467.

BOGDANOV, Y. F., KOLOMIETS, O. L., LYANPUNOVA, E. A., YANINA, I. Y. AND MAZUROVA, T, F. 1986. Synaptonemal complexes and chromosome chains in the rodent Ellobius talpinus heterozygous for ten Robertsonian translocations. Chromosoma, 94, 94-102.

BRAMBELL, F. W. R. 1935. Reproduction in the common shrew (Sorex araneus Linnaeus). II. Seasonal changes in the reproductive organs of the male. Phil. Trans. R. Soc., B225, 51-62.

BURGOYNE, P. S. AND BAKER, T. G. 1984. Meiotic pairing and gametogenic failure. Symp. Soc. Exp. Biol., 38, 349-362.

COMINGS, D. E. AND AVELINO, E. 1972. DNA loss during Robertsonian fusion in studies of the Tobacco mouse. Nature New Biology, 237, 199.

ELDER, F. F. B. AND PATHAK, S. 1980. Light microscopic observations on the behavior of silver-stained trivalents in pachytene cells of Sigmodon fulviventer (Rodentia, Muridae) heterozygous for centric fusion. Cytogenet. Cell Genet., 27, 31-38.

FEDYK, S. 1980. Chromosomal polymorphism in a population of Sorex araneus L. at Bialowieza. Folia Biol., 28, 83-120.

FORD, C. E. 1972. Gross genome unbalance in mouse spermatozoa: Does it influence the capacity to fertilise? In Beatty, R. A. and Gluecksohn-Waelsch, S. (eds) The Genetics of the Spermatozoa, Edinburgh, pp. 359-369.
FREDGA, K. 1970. Unusual sex chromosome inheritance in mammals. Phil. Trans. R. Soc. Lond., B259, 15-36.

GARAGNA, S., ZUCCOTTI, M., SEARLE, J. B., REDI, C. A. AND WILKINSON, P. J. 1989. Spermatogenesis in heterozygotes for Robertsonian chromosomal rearrangements from natural populations of the common shrew, Sorex araneus. J. Reprod. Fert. 87, 431-438.

GOSDEN, J. R., LAWRIE, S. S. AND GOSDEN, C. M. 1981. Satellite DNA sequences in the human acrocentric chromosomes: information from translocations and heteromorphisms. Am. J. Hum. Genet., 33, 243-251.

GROPP, A. AND WINKING, H. 1981. Robertsonian translocations: Cytology, meiosis, segregation patterns and biological consequences of heterozygosity. Symp. zool. Soc. Lond., 47, 141-181.

HALKKA, L. AND SÖDERLUND, v. 1987. Random NOR-activation in polymorphic and stable chromosomes of Sorex araneus L. Hereditas, 106, 293-294.

HALKKA, L., HALKKA, O., SKARÉN, U. AND SÖDERLUND, V. 1974. Chromosome banding pattern in a polymorphic population of Sorex araneus from northeastern Finland. Hereditas, 76, 305-314.

HUltén, M. A., SAADAllah, N., WALlaCe, B. M. N., AND CREASY, M. R. 1985. Meiotic studies in man. In Rooney, D. E. and Czepulkowski, B. H. (eds) Human Cytogenetics: A Practical Approach, IRL, Oxford, pp. 163-196.

JOHANNISSON, R., GROPP, A., WINKING, H., COERDT, W., REHDER, H. AND SCHWINGER, E. 1983. Down's syndrome in the male. Reproductive pathology and meiotic studies. Hum. Genet., 63, 132-138.

JONES, G. H. AND WALlACE, B. M. N. 1980. Meiotic chromosome pairing in Stethophyma grossum spermatocytes studied by a surface-spreading and silver-staining technique. Chromosoma, 78, 187-201.

KODAMA, Y., YOSHIDA, M. C. AND SASAKI, M. 1980. An improved silver-staining technique for nucleolus organizer regions by using nylon cloth. Jap. J. Hum. Genet., 25, 229-233.

MEYLAN, A. 1964. Le polymorphisme chromosomique de Sorex araneus L. (Mammalia; Insectivora). Rev. Suisse Zool., 71, 903-983.

MOSES, M. J. 1977. Synaptonemal complex karyotyping in spermatocytes of the Chinese hamster (Cricetulus griseus). I. Morphology of the autosomal complement in spread preparations. Chromosoma, 60, 99-125.

MOSES, M. J., KARATSIS, P. A. AND HAMILTON, A. E. 1979. Synaptonemal complex analysis of the heteromorphic trivalents in Lemur hybrids. Chromosoma, 70, 141-160.

OLERT, J. AND SCHMID, M. 1978. Comparative analysis of karyotypes in European shrew species. I. The sibling species Sorex araneus and $S$. gemellus: Q bands, G bands and the position of NORs. Cytogenet. Cell Genet., 20, 308-322.

PATHAK, S. AND LIN, C. C. 1981. Synaptonemal complex of the sex-autosome trivalent in a male Indian muntjac. Chromosoma, 82, 367-376.

REDI, C. A. AND CAPANNA, E. 1988. Robertsonian heterozygotes in the house mouse and the fate of their germ cells. In Daniel, A. (ed.) The Cytogenetics of Mammalian Autosomal Rearrangements, Liss, New York, pp. 315-359.

REDI, C. A., GARAGNA, S., MAZZINI, G. AND WINKING, H. 1986. Pericentromeric heterochromatin and A-T contents during Robertsonian fusion in the house mouse. Chromosoma, 94, 31-35.

RICHLER, C., ULIEL, E., ROSENMANN, A. AND WAHRMAN, J. 1989. Chromosomally derived sterile mice have a 'fertile' active XY conformation but no XY body. Chromosoma, 97, 465-474. 
ROSENMANN, A., WAHRMAN, J., RICHLER, C., VOSS, R., PERSITZ, A. AND GOLDMAN, B. 1985. Meiotic association between the XY chromosomes and unpaired autosomal elements as a cause of human male sterility. Cytogenet. Cell Genet., 39, 19-29.

SEARLE, J. B. 1983. Robertsonian Chromosomal Variation in the Common Shrew Sorex araneus L. Ph.D. Thesis, University of Aberdeen.

SEARLE, J. B. 1986a. Factors responsible for a karyotypic polymorphism in the common shrew, Sorex araneus. Proc. $R$. Soc. Lond., B229, 277-298.

SEARLE, J. B. $1986 b$. Meiotic studies of Robertsonian heterozygotes from natural populations of the common shrew, Sorex araneus L. Cytogenet. Cell Genet., 41, 154-162.

SEARLE, J. B. 1988 a. Karyotypic variation and evolution in the common shrew Sorex araneus. In Brandham, P. E. (ed.) Kew Chromosome Conference III, HMSO, London, pp. 97107.
SEARLE, J. B. $1988 \mathrm{~b}$. Selection and Robertsonian variation in nature: the case of the common shrew. In Daniel, A. (ed.) The Cytogenetics of Mammalian Autosomal Rearrangements, Liss, New York, pp. 507-531.

SHARMAN, G. B. 1956. Chromosomes of the common shrew. Nature, 177, 941-942.

SHARP, P. 1982. Sex chromosome pairing during male meiosis in marsupials. Chromosoma, 86, 27-47.

śWitoński, M., GUSTAVSSON, I. AND PLOEN, L. 1987. The nature of the 1;29 translocation in cattle as revealed by synaptonemal complex analysis using electron microscopy. Cytogenet. Cell Genet., 44, 103-111.

WOLF, K. W. AND WINKING, H. 1989. The mode of Robertsonian translocations in the house mouse (Mus musculus). Abstracts to the 10th International Chromosome Conference, Uppsala, Sweden, June 18-22, 1989. 